\title{
Synthesis of Modified Carbon Catalysts and Investigation of its Catalytic Activity in Reactions of Hydrocracking of Hydrocarbons on Two-stage Laboratory Setup
}

\author{
S.K.Tanirbergenova, N.K.Zhylybayeva, A.B.Issayeva, G.M.Moldazhanova, Z.A.Mansurov \\ Institute of Combustion Problems, Kazakhstan
}

K.Zhumakhan,

SPTC “Jalyn” LLP, Kazakhstan.

050012, Kazakhstan, Almaty, 172, Bogenbai Batyr str.

\begin{abstract}
This paper presents the results concerning investigation of hydrocracking hydrocarbons on modified carbonaceous catalysts which were obtained by impregnation and coating of metals with using of Tonkeris (name of region) clay. The influence of obtained modified carbon catalysts on catalytic activity and stability in hydrocracking reactions of hydrocarbons on the enlarged iso-and hydrocracking setup were investigated.
\end{abstract}

KEYWORD: carbon; catalyst; cobaltmolybdenum catalyst; hydrogenation; hydrocarbons; hydrocracking; isocracking

\section{INTRODUCTION}

Scientific interest in the field of petrochemistry largely depends of the development of new catalysts and catalytic processes. The search of new catalytic systems, the study of their properties, regularities and ways of its preparing is one of the most important tasks of hydrogenation hydrocarbons process. Due to the rapid development of high-tech and waste-free technologies, as well as continuously expanding needs for effective catalysts of latest generation the development of new metalcarbon catalysts is of particular relevance[1-3].

In this work with the purpose of replacement of expensive catalysts on the base of aluminum oxide and zeolites which are containing the platinum group metals, the work on creation of nanostructured catalysts are supported on porous carbon carriers and modified by metals was carried out. A material which is prepared by carbonization of clay in the laboratory of carbon nanomaterials of the Institute of Combustion Problems was selected as carbon carrier.

\section{EXPERIMENTAL PART}

The formation process of the catalytic carbon of Tonkeris clay from Akmola region in the presence of pyrolysis of propane-butane mixture was investigated. Carbonization is carried out by the method which was developed in the laboratory of hybrid technologies of the Institute of Combustion
Problems[4], in a circulating flow setup in the temperature range of $600-900^{\circ} \mathrm{C}$ under the regime of propane-butane mixture with duration of pyrolysis of 30-60minutes. The clay which was prepared by extrusion on granulator is dried at room temperature, then heated in a muffle for 2 hours at $450^{\circ} \mathrm{C}$ and cooled in air to room temperature.

The modified carbon catalysts were prepared as follows: the clay is soaked with metal salt solutions, granules were formed with a diameter of $1 \mathrm{~mm}$ and with length of $2-3 \mathrm{~mm}$. The dependence of deposited carbon amount on the number of metals with mixed valence is established. The dependence of the catalytic activity and selectivity of the modified carbon catalysts in the hydrocracking hydrocarbons processes from the temperature and catalyst composition is determined.

Conversion of n-hydrocarbons on new catalyst systems was studied on two-stage laboratory setup in flow reactor with a volume of catalyst of $14 \mathrm{~cm}^{3}$ at a temperature of $250-550^{\circ} \mathrm{C}$, volume rate of $\mathrm{n}$ hydrocarbon of $10-20 \mathrm{ml} / \mathrm{min}$ in the absence and under pressure of hydrogen to $30 \mathrm{~atm}$.

Analysis of liquid and gaseous reaction products was performed by gas-liquid chromatography method on Chromatograph "Chromatek-Crystal 5002”.

\section{RESULTS AND DISCUSSION}

The formation of catalytic carbon at the surface of clay is modified by metals in hydrocarbons pyrolysis 
process it gives a possibility to examine such system as a new catalyst with predetermined characteristics. The morphology originality of catalytic carbon and its formation on mineral basis is determine their catalytic properties. Modification of carbon materials with metal ions extends the scope of their use as catalysts for various destinations.

The results of electron microscopy stated that nanostructurized metalcarbon catalysts with the sizes of metal particles of $10-40 \mathrm{~nm}$ were synthesized (Fig.1 a). Also, carbon fibers and nanotubers were detected (Fig.1 b).
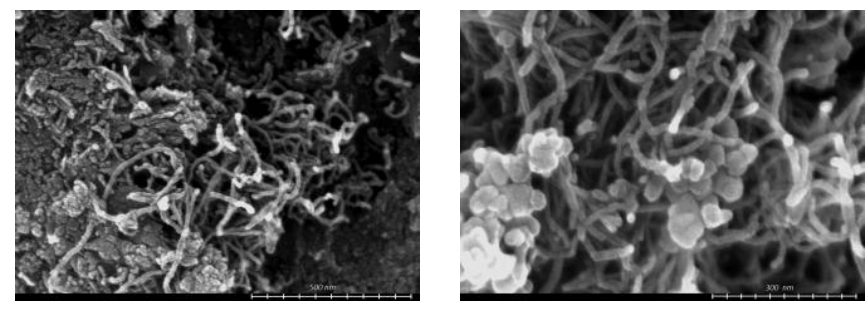

Figure 1. Electron microscopic pictures of cobaltmolybdenum catalyst

X-ray phase analysis on cobaltmolybdenum catalyst allowed to detect the existence of muscovite, quarts, silicon carbide, molybdenum oxides and reduced cobalt in nanocarbon catalysts[5].

The temperatures of the spectrum obtained allow to suppose that EPR line with $\mathrm{g}=4.3$ is associated with isolated, weakly interacting iron complexes which are in a strong rhombic distortions of the coordination point. The line with $\mathrm{g}=2.1$ is caused by interacting between each iron complexes with light distortions point.

The intensity ratio of these lines in the sample being studied shows that about $5 \%$ of three valent ions are in isolated state $(\mathrm{g}=4.3)$.

In obtaining process of metal-carbon catalysts the increasing of specific surface area up to carbonization temperature of $750^{\circ} \mathrm{C}$ and its decreasing with further temperature increase is determined, and connected with the formation of a solid graphitized carbon. It is deducted from experiments that by carbonization method we can get more advanced surface with high porosity than the original samples. This is due to the formation filamentous carbon in the depositional process on the surface of the samples.

Thus, the obtained catalysts have a high surface area, porosity, as well as on these carriers we can obtain highly active catalysts with a minimum metal loading. In accordance with standard procedures we determined the bulk density, strength and specific surface according to the method of thermal desorption of argon.

The synthesized catalysts Tonkeris clay were studied in the processes of hydrocracking of decane and hexane. Cobaltmolybdenum catalysts we obtained and investigated the samplers containing Co, Mo components. On cobaltmolybdenum catalysts it was shown that conversion of hexane made up $87 \%$ and that of decane $-73 \%$. Figure 2 presents the dependency of a total yield of olefins of decane and hexane hydrocracking on the temperature on the temperature on the catalyst with the content of $5 \% \mathrm{Co}$ and $0.5 \%$ Mo at $25 \mathrm{~atm}$. With rise of temperature in liquid reaction products at hexane hydrocracking reactions at $550^{\circ} \mathrm{C}$ makes up $50 \%$ (Fig.2).

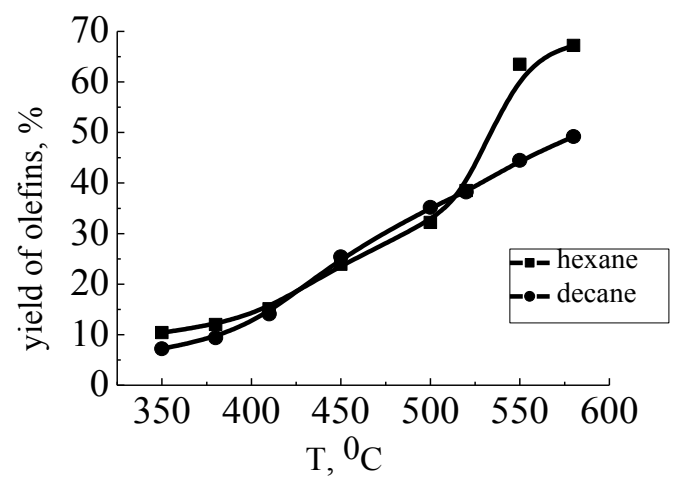

Figure 2. The dependency of the yield of olefins on the temperature in hydrocracking processes of decane and hexane

Figure 3 shows the dependency of total yield of isomers of decane and hexane hydrocracking on the temperature on the catalyst containing $5 \% \mathrm{Co}$ and $0.5 \%$ Mo at the pressure of $25 \mathrm{~atm}$. With the rise of temperature in liquid reaction products at $450^{\circ} \mathrm{C}$ maximum total yield of makes up 30\%.

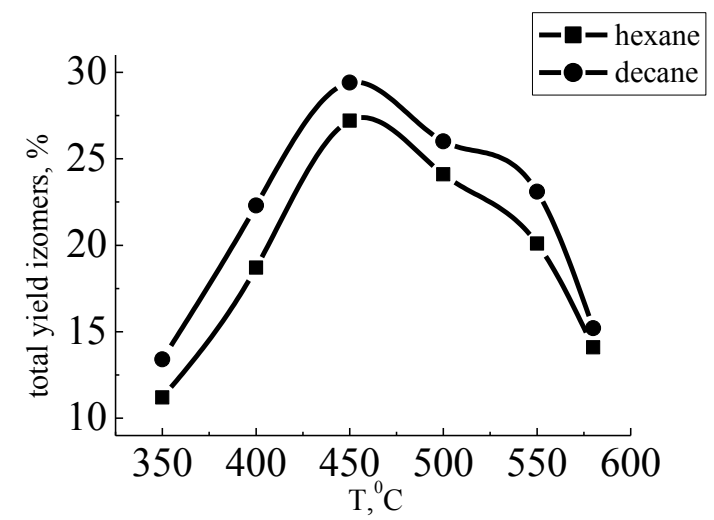

Figure 3. The dependency of the total yield of isomers on the temperature in hydrocracking processes of decane and hexane

The catalytic activity of prepared metal-carbon catalysts were investigated in reactor of hydrocracking hendecane. According to result of hydrocracking at high temperatures up to $10 \%$ of cobalt-molybdenum catalyst, the gas phase output is increased to $50-60 \%$. The hydrocracking hendecane was conducted at the temperature of $350^{\circ} \mathrm{C}$ depending of the pressure (first reactor). Figure 4 shows the yield of gas phase and isomers depending on the pressure[6]. 


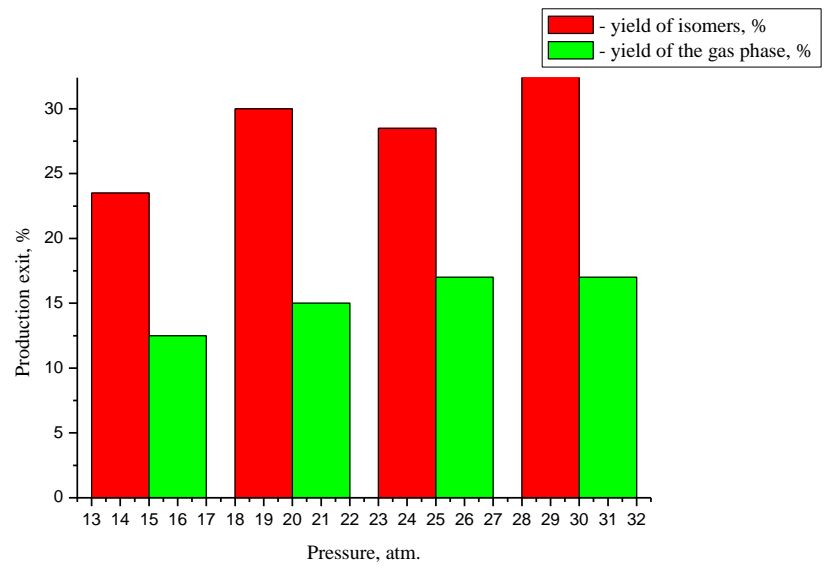

Figure 4. The yield of gas phase and isomers depending on pressure in hydrocracking reactor

Due to undertaken study it was found that the yield of gas phase is increased with temperature rising. The concentration of active substance in reaction medium also has a significant influence on the reaction path. An increasing of concentrations of modified metals up to $10 \%$ of cobalt, $5 \%$ of Mo leads to a significant increase in the yield of liquid phase. With further increase in concentration of modified metals the yield of liquid phase is decreased and the gas phase is reduced.

The catalytic activity of prepared palladium catalysts were investigated in the reactor of isocracking of undecane products. Figure 5 shows the results of isomerization products from the first reactor at a constant temperature, depending on the pressure in the second reactor.

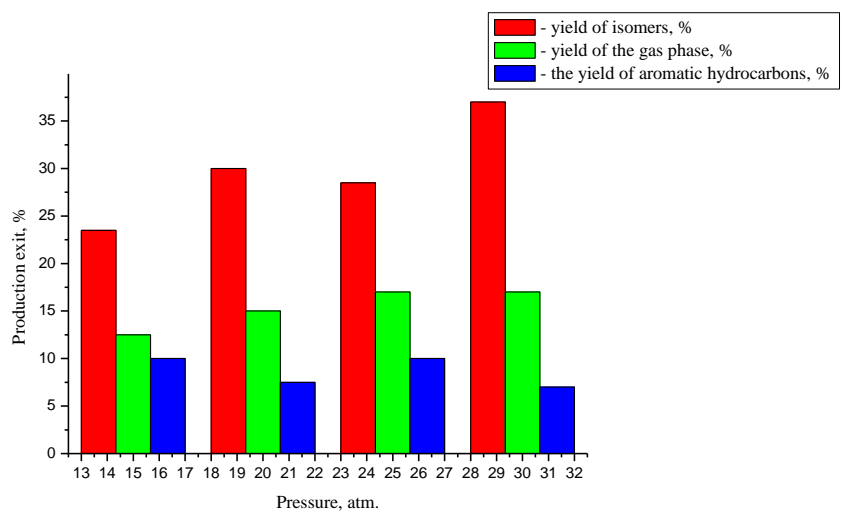

Figure 5. The yield of gas phase and isomers depending on pressure in reactor of isocracking
In the second reactor at a temperature of $300^{\circ} \mathrm{C}$ the yield of isomers is $35 \%$. A palladium catalyst promotes to the formation of isomers. As we can see from figure 2 under the given conditions the formation of aromatic hydrocarbons is fixed. At increasing of pressure, the yield of aromatic hydrocarbons is decreased.

Thus, as a result the high-efficiency carbon catalysts are developed and synthesized, are modified by cobalt and cobalt-molybdenum. The influence of obtained modified carbon catalysts on catalytic activity in the reactions of hydrocracking hydrocarbons on enlarged iso-and hydrocracking setup is investigated.

The optimal process conditions for hydrocracking undecane in first reactor on cobaltmolybdenum catalyst: $\mathrm{T}=500^{\circ} \mathrm{C}, 30 \mathrm{~atm}$. where as the result of conversion of hydrocarbons such elements as $38 \%$ C5 $33 \% \mathrm{C}_{6}$ and $\mathrm{C}_{2}-\mathrm{C}_{3}$, and $8 \%$ aromatic hydrocarbons were foemed.

\section{REFERENCES}

[1] Palmer E.R., Kao S.H., Tung C., Shipman D.R. Consider options to lower benzene levels in gasoline. New regulations further limit this aromatic from the refinery blending pool. Hydrocarbon Processing, 2008. P. 55-66.

[2] Alvisi M., Galtieri G., Giorgi L., Giorgi R., Serra E., Signore M.A. Sputter deposition of Pt nanoclusters and thin films on PEM fuel cell electrodes. Surface and Coating technology, 2005. Vol. 200. P. 1325-1329.

[3] Ysmael Verde, et al. Active area and particle size of $\mathrm{Pt}$ particles synthesized from $\left(\mathrm{NH}_{4}\right)_{2} \mathrm{PtCl}_{6}$ on a carbon support. Catalysis today, 2005. Vol. 107-108. P. 826-830.

[4] Dinistanova B.K., Tanirbergenova S.K., Bijsenbaev M. A., Mansurov Z.A. Syntesis of carbonmaterials. $2^{\text {nd }}$ NanoIntregration Conference "Quality in nanosafety assessment - driving best practice and Innovation, Czech Republic, Prague, $27^{\text {th }}$ February $-1^{\text {st }}$ March 2013. P. 90.

[5] Dinistanova B.K., Ablayhanova N.T., Tanirbergenova S.K., Bijsenbaev M.A., Mansurov Z.A. Syntesis of carbon nanomaterials and their use as modifiries of composites. $44^{\text {th }}$ World Chemistry Congress, Turkey, Istanbul, 11-16 August 2013. P. 1351.

[6] Tanirbergenova S.K., Zhylybayeva N.K., Dinistanova B.K., Moldazhanova G.M., Ernazarova A.G., Mansurova R.M., Mansurov Z.A. Nanostructured metalcarbon catalysts in the process hydrocracking of hydrocarbons. $44^{\text {th }}$ World Chemistry Congress, Turkey, Istanbul, 11-16 August 2013. P. 1357. 